\title{
Study on Aesthetic Value of China Propaganda Poster
}

\author{
Jinsong $\mathrm{Yu}^{1, \mathrm{a}^{*}}$ and Shengli Chen ${ }^{2, \mathrm{~b}}$ \\ ${ }^{1}$ School of Art and Design, Wuhan University of Science and Technology, Wuhan, China \\ ${ }^{2}$ School of Design, Jianghan University, Wuhan, China \\ ayujinsong@wust.edu.cn, $527395960 @ q q . c o m$ \\ * the corresponding author
}

Keyword: Propaganda poster; Aesthetic value; Social value; Art value

\begin{abstract}
Social value and artistic value construct aesthetic value connotation of propagand a poster from two aspects of internal and external. First, the social value to show the beau ty of spirit, covers the beauty of morality, human nature, social fairness and justice, human and nature harmonious coexistence; Second, the artistic value to show the beauty of form, covering the beauty of artistic conception, composing, color etc.
\end{abstract}

\section{Introduction}

Propaganda Poster. Propaganda Poster is an important concept that appears in the field of graphic design in the middle and late twentieth Century. It is also an important component of the graphic design category. This concept originated in western modern art movement in the first half twentieth Century. After World War II, as a design project hosted by the government, propaganda poster has a unique style and outstanding artistic level in socialist countries Poland. Simultaneously, it is the representative of the most typical design sects with the characteristics of two aspects: national requirements and designers' personal ideas, which has attracted widespread attention in graphic design field of the world. The new China propaganda poster also is known as the poster that originates in the Soviet Union. It is a kind of painting for the purpose of propaganda, making public opinion and atmosphere, usually refers to political posters. Furthermore, it also includes cultural activities posters and commodity advertising, etc. Generally with a striking, appealing and passionate headline. This kind of poster is characterized by striking image, outstanding theme, lively style and inspiring power. Posters are usually posted or drawn in some public places where people are concentrated, play a social role in a timely manner by directly facing the masses and influencing people's minds. Propaganda posters have strong political and cultural contents because of its important part of art creation in Chinese revolutionary war and socialist construction period. According to the uses of propaganda poster, They can be divided into political propaganda picture, film propaganda picture, cultural propaganda picture, sports propaganda picture, health propaganda picture, etc.

Aesthetic Value. The aesthetic value means that the natural ecosystem use its vitality, different poses scenery to created economic benefits in the process of people recuperating. Aesthetic value is a judgment of value based on the appearance of an object and the emotional responses it evokes. While it is difficult to objectively assess aesthetic value, it often becomes an important determining factor in overall value; things people perceive as attractive tend to be in higher demand, and will cost more than comparable objects without the aesthetic component. An objective theory claim (roughly) that aesthetic value somehow resides in properties of the work itself, such that any reasonably competent observer would find them.

\section{Aesthetic Value of Propaganda Drawing}

The Function of Art. The social function of art should be based on the aesthetic value. And it has functions of cognition, aesthetic and educational. Art, first and foremost, is in line with the aesthetic needs and standards of the general public so that everyone can become acquainted with 
the arts and then create aesthetically pleasing, and then produce the educational function to achieve its social function. Therefore, only when the aesthetic value is realized, it will have an influence and mold, and social functions and values will be produced.

On the spiritual level, art is a field of culture or a form of cultural value. When it is juxtaposed with religion, philosophy, ethics, etc., its aesthetic thoughts will be revealed, and produce social influence.

At the level of the activity process, art is the artist's self-expression, creative activity, or imitation of reality. If this performance itself is not beautiful, bring no follow-up anything.

As a result level of activity, art emphasizes the objective existence of art. It is generally believed that art is a way for people to grasp the real world. Art activity is a spiritual practice where people grasp an objective object in an intuitive and holistic way and create a certain artistic image in symbolic form.

Thus, it can be seen that the propaganda posters appeared in the form of artwork are not only the artist's understanding and reflection of the objective world, but also the subjective factors such as the artist's own emotions, ideals and values. It is a spiritual product, and when this spiritual product is more beautiful and nobler, its value is greater, and its social function is better. Therefore, the aesthetic value of propaganda posters embodies both internal and external levels: social value and artistic value. Social value shows the beauty of morality, the beauty of human nature, the beauty of social fairness and justice, the beauty of harmony between man and nature; Artistic value displays the forms of beauty include its own artistic conception, composition, color.

Social Value and Spiritual Beauty. Social value refers to the contribution and responsibility that people make through their own and self-actualizing activities to meet the material and spiritual needs of the society or others. Therefore, the social value of the propaganda posters is to show the beauty of morality, the beauty of human nature, the beauty of social fairness and justice, and the beauty of the harmonious coexistence between man and nature through the content and subject matter of the works. It establishes an interaction relationship to the audience in a specific pictorial language and a clear theme. At the same time, to meet the spiritual needs of the society or audience in this process.

Propaganda posters' arousing people's patriotism to promoting unity and social harmony is one important aspect of social value. For example, one of the series painting of "the old ape's hundred posture" Fig. 1 created by Qian Binghe in 1913, mainly used the comics, woodcuts and other art forms to expose the Qing government's corruption and incompetence in front of the Western imperialists' aggression. At the same time, it also transmitted the message of the country's danger to the public with the art form of the combination of humor and satire. It effectively inspires and enhances the people's patriotism to save the nation.

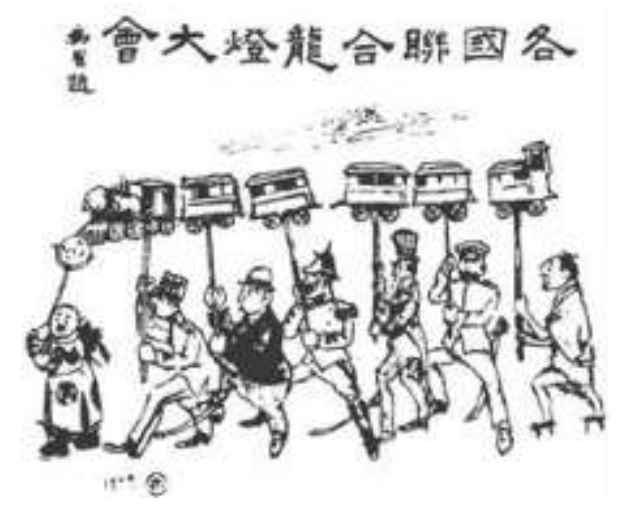

Figure 1. A Poster of "The Old Ape's Hundred Posture"

The propaganda poster of "learning Daqing spirit" Fig. 2 created by Ha Qiongwen is to sing the praises of the moral beauty of the laborer to his job. On this picture, it can be seen that the iron man named Wang Jinxi who was exploiting petroleum in the snowstorm, he wears a hat, with resolute 
facial contour, perseverance smile, standing in the freezing weather without any fear, all highlight the spirit of the iron man. The visual focus is on the Iron man's pocket with a book showing the part of the book, revealing a copy of Chairman Mao's book. The creator linked the Iron man spirit of hard-working with Mao Zedong Thought to cleverly interpreted the moral spirit of an ordinary human being.

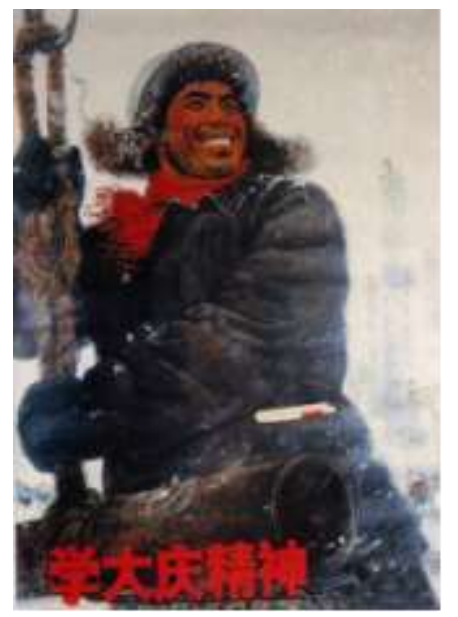

Figure 2. A Poster of "Learning Daqing Spirit"

"Help Mom Learning Culture" Fig. 3 is a poster made by Yu Yunjie, which shows that a little girl seriously teaches her mother to learn the culture. The painting adapts to the real needs of the times to disseminate the campaign of elimination of illiteracy. The content of the pictures also naturally and internally gives rise to the contrast between old and new in one's mind: poverty, turmoil and feudal ethics in the old society have made it impossible for ordinary women Education; and the establishment of a new society not only liberates women but also gives them equal access to education. The warm scenes of mother-daughter interaction learning cause the audience deeply appreciate the peace and happiness of today. Simultaneously, a wonderful feeling of embracing and loving the new regime arise in their heart. According to this picture, it also can be observed that the propaganda poster may activate the group's patriotic enthusiasm to show and promote fair and equitable justice to achieve subtle publicity.

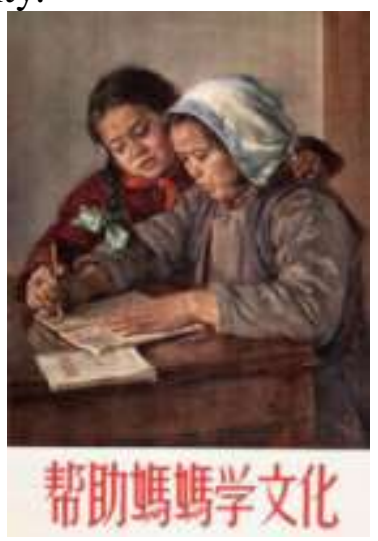

Figure 3. A Poster of "Help Mom Learning Culture"

It can be seen that the poster conforms to the development of the times and closely follows the pulse of the times. It not only helps transform the spiritual outlook of the whole society but also promotes the harmonious development of society.

Artistic Value and Formal Beauty. The artistic value of the propaganda poster shows its own artistic conception, composition, color and other forms of beauty. While presenting various themes, its visual expression has also been shown differently. As a creator of posters, not only to convey a specific subject matter, but also to express an ideal and feelings. 
The development of technology used in the design of the poster often produces a unique visual beauty. For example, the simplification of the production process of early posters has benefited from the application of color photography technology, photographic techniques and spray gun technology. At the same time, the poster creators are also influenced by the surging style and genre of contemporary realism and naturalism. As well as adopting the three-dimensional images of modernist, abstract and symbolic approaches to replace the conservative appearance of the plane poster to rich the thematic expressions of posters.

There are changes and breakthroughs in the visual performance. The first is that the creators select specific things to refine and summarize based on the theme of expressing to transform the visual symbols from concrete images to abstract and concise geometric forms, giving a connotation of cultural value, in order to embody the subject and convey the information to the audience. Such as the creation of Chen Shaohua's "anti-Nazi" Fig. 4, in the picture, there is no Hitler, no Nazi troops, while only the Nazi symbols; the background is a red cross on justice, and a squeezed Nazi symbols in it, briefly expressed anti-Nazi theme. The poster uses a concise graphic representation of the geometry to create a strong visual appeal that makes it easy for the audience to think of themes from shapes. Second, while pursuing visual conciseness, it emphasizes the unity of style and interest in formal language. It not only guarantees the audience's cognition of familiar things but also subverts their inherent understanding to ensure that the audience has a certain distance with the known Information, and a certain space of imagination.

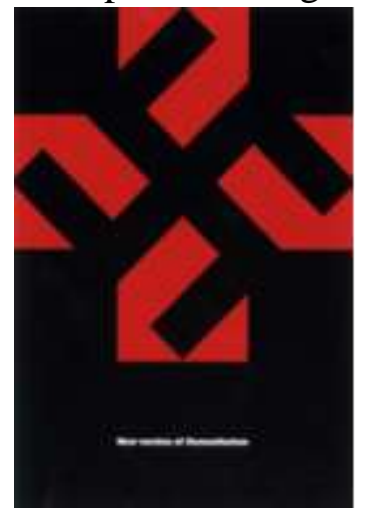

Figure 4. A Poster of "Anti-Nazit"

In the composition of color, according to the basic theory and principle of psychology, physiology, cleverly use color on the human psychology, physical influence and appeal to express a variety of inherent emotions, so that the audience feel creator's ingenious expression, resulting in a visual surprise. On the other hand, people in different regions, customs, national traditions and daily life have great differences in understanding of color, such as white color, it represents holy in the West, but ominous in the East. However, the combination of color and a specific image will be given a clear meaning and has universal significance. For example, the poster of "protecting the legitimate rights and interests of women and children" Fig. 5. In front of the picture is a woman holding a child, they are enveloped in orange warm colors, people feel they have a sense of security. And behind the picture is a black silhouette of the bad guy inside the dark prison window behind. The main contrast of the light and dark of the picture is strong, clearly highlighting the theme of posters, but also full of a rich sense of form. 


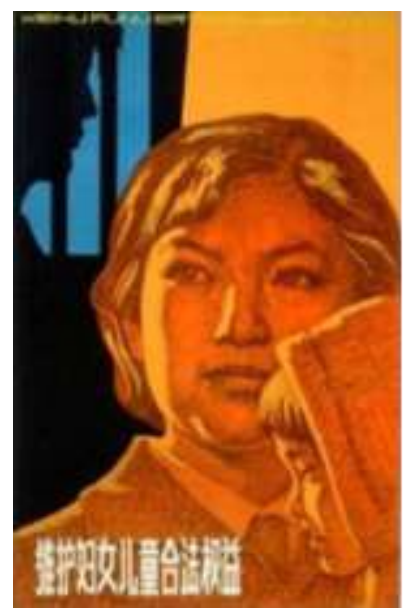

Figure 5. A Poster of "Protecting the Legitimate Rights and Interests of Women and Children"

Thus, the constant updating of design concepts, the application of new technologies and the diversity of forms will promote the better effect and expressiveness of posters, and based on the practical value they will have a stronger visual artistic expression, the beauty of form also fully demonstrates the artistic value of posters.

\section{Propaganda Poster Keeping Pace with the Times}

With the development of society, the focus of publicity paintings continue to expand, many works express the content of social welfare, pay attention to the environment and ecology, social morality and fashion, love, aid and dedication, etc. In 2016, WWF hosted the Public Art Poster Design Contest with the theme of "Green Office" in the China Division. Poster designers from around the world participated in the public interest poster creation activities and many good works appeared. The author of this paper also carried the work "Plug or Unplug for Green House" to participate in the competition, and was finally lucky to be selected by the organizers, and exhibited at the Shanghai branch. In this piece, the author chose the abstract geometry and popular network icon symbols to integrated design and generate the final graphic of two emoticons. The entire work with green as the core concept use graphics and thematic slogan to a combination, intuitively and clearly convey the message, express the theme of the concept. meanwhile, it also shows that the aspects of poster 's designing, producing and transmitting and carriers has to renew to keeping up with the pace of the times with the progress of the technology.

\section{Conclusion}

Today, with the development of the media, the effect of posters has been replaced largely by the media, such as television, the Internet, but posters still play an important role in inspiring. Although its function has undergone tremendous changes, its aesthetic value connotation is still sustainable. That is to say, through the interaction between the content, the theme of the works and the audiences, the propaganda poster's social value shows the beauty of moral that include the fairness And justice of humanity and social, the harmonious of man and nature; The value of art shows its beauty of form, composition, and color.

\section{Acknowledgements}

This work is supported by the "Humanities and social science guidance Program NO: 14G117" which is granted by Hubei Provincial Department of Education, Wuhan, China, in 2014.

The authors would like to thank Professor Yong Zeng for providing resources for research opportunity, research equipment, and research methodology. 


\section{References}

[1] Why the various social functions of art must be based on the aesthetic value? Retrieved June 2016, from https://zhidao.baidu.com/question/2011441867036459188.html

[2] Zeng, Y. \& Cheng, G. (1991). On the Logic of Design. Design Studies, 12(3), 137-141.

[3] YU, J. S. \& Chen, S. L. (2016). Validation of Recursive Logic in Graphic Design. Journal of Integrated Design and Process Science, 1-15.

[4] Landsberger and Marien Van Der Heijden. Chinese Posters: The Iish-Landsberger Collections [G].Prestel Art Books, 2009.

[5] Julia F. Andrews. Painters and Politics in the People's Republic of China, 1949-1979[M]. University of California Press, 1994.

[6] $\mathrm{Fu}-w u$ Hou. To change a nation: propaganda and indoctrination in Communist China [M].Free Press of Glencoe, 1961.

[7] Alan P. L. Liu. Communications and national integration in Communist China [M].University of California Press, 1971. 